\title{
Challenges and Strategies of Higher Education against the Background of Mobile Media
}

\author{
Hongxia Li \\ Associate Professor. Peking University \\ Dr. Beijing sport University \\ Beijing, China \\ 1hx1841@hotmail.com
}

\author{
Sumeng Xu \\ Master, Beijing sport University \\ Beijing, China \\ 991223648@qq.com
}

\begin{abstract}
Mobile Media has the audience, informative and wide; portability, time-sensitive; disseminate more targeted content and so on. With easy auxiliary functions to guide public opinion. The current popularity of mobile media has brought four challenges to higher education. As in the case of mobile media context, the elements of traditional education changes; mobile media challenge to traditional education content; mobile media challenge to the ideological and political education. mobile media challenge to college students self-management skills. Faced with this challenges brought by mobile media for higher education, higher education colleges should change their concepts; Strengthen research and education reform model, actively a new online education initiative occupying positions; strengthen the construction of teachers, emphasis Mobile Media Research, enhance the capability of mobile media network public opinion judged, and strengthen monitoring and guidance; strengthen students' ability to self- educate and guide students on the proper use of mobile media.
\end{abstract}

Keywords - the Mobile Media; Higher Education; Challenges; Strategies; MOOC

\section{INTRODUCTION}

At present, China Mobile business is developing very rapidly. From January to May in 2012, the national mobile phone users increased by 54.471 million, reaching 1.040724 billion. Among them, $3 \mathrm{G}$ users increased by 38.251 million, and reached 166.675 million.[1] As the $3 \mathrm{G}$ era, there is a higher and higher percentage of mobile phone users for searching the Internet in the mobile phone user group. In the first half of this year, the access to Internet of China's Internet users presented a new pattern: To China's Internet users, the mobile phone has become the biggest access to the Internet terminals. By the end of June 2012, the scale of China's mobile phone cyber citizens reached 388 million, by contrast, through the desktop, Internet users was 380 million.[2] With the rapid development of communication technology, smart phone has added some entertainment functions, such as music, video player, taking pictures, recording, Internet, taobao on the basis of its original functions of calling and texting and it also can carry all kinds of office software, stock software, reading software, etc. The major reasons why mobile phone become popularized lie in the gradually enriched functions as well as the daily lowered cost. In addition, the portability of the phone itself, that is to say, the prompt function, also plays an important role. The 3G, 4G mobile network can break through the limitations of computer terminals, almost at the same pace with the news. The independent status to attract the audience has improved and it can freely choose and release information. The information's being timely and interactive makes interpersonal communication and mass communication perfectly combine with each other, so that the mobile phone becomes the fifth media following the newspapers, radio, television and Internet.

In addition to wallets and mobile phones have become the third largest foreign keys accoutrements. The PC Magazine columnist once said: "The mobile phone has become the world's most popularized portable equipment in the public and there is only mobile phone in everyone's pocket besides keys and wallets." With its inherent advantage of communication interaction and gaining information, people take it at least 12 hours every day as a medium with body warmth. On college campus, mobile phone has become the indispensable equipment for the college students. The phenomenon of "one person with one phone" can be seen everywhere, even in the restaurant, dormitory, or street. There was even a joke in the world's most remote distance in front of me, but you look down at your phone. The mobile media, which has popularized, has the advantages over other media. There are also many negative impacts that can not be ignored. Therefore, the popularity of mobile phone media in colleges and universities is bound to bring the inevitable impact and challenge on the development of higher education.

\section{THE CHARACTERISTICS OF MOBILE PHONE MEDIA}

\section{A. Large Audience, Wide Information}

Communications World Network News (CWW) global technology research and advisory firm Gartner latest survey report, the total number of Chinese mobile phone users in 2013 for the first time more than one billion. Analysts Gartner predict that by 2014 , the Chinese market will sell 443.5 million mobile phones, and the use of mobile phones will be more than 1.075 billion.[3] The data show that compared with the domestic outdoor media largest circulation newspaper, magazine, website hits highest and largest passenger railway stations, subway and other places, the number of mobile media has a much larger, broader audience type. The measure is an important factor in a competitive media is the reality and 
the potential number of audience for mobile media, the most worry is that users do not need the resources. Mobile Media at such a high level of popularity coupled with its interpersonal communication, organizational communication and mass communication trait aspects of making information can spread very quickly among users. Have to admit, convenience and speed of mobile media means of communication spread rapidly increase the scope and impact of the amount of information.

\section{B. Portability, Time-Sensitive}

Mobile Media mobile network broke the limit of space, time, making the exchange of information between becoming anywhere. Whether users are in wherever come up with all kinds of information on the phone, news, sports, entertainment, culture, and life can be mastered for the first time, do not worry about missing important news. It was the image of the mobile media called "shadow" media, because most people tend to be the current machine leave the body, mobile media with its advantage of portability, mobility is achieved while walking .Levinson believes that human beings have two basic modes of communication: talk and walk. Since the birth of the human self pity, began to split these two functions, until the phone turned out, these two functions relative to integrate rolled into one.[4] American "Columbia" space shuttle shocked the world, television, newspapers, radio, Internet four major media coverage, but the fastest action is SMS. Less than 10 minutes after the incident, the major portals Sina and put in 10 minutes of sending the message to the user's mobile phone. The most recent issue of Malaysia Airlines MH730 lost contact affects the hearts of people around the world, many people are also concerned by the phone in real-time progress of the event. So that most can not be watching TV or using the computer reports that people get the latest information on current events, plus mobile phone users can edit each other after forwarding to compensate for the lack of other media, including the network.

\section{More Targeted Dissemination of Content, Ease of Auxiliary Guide Public Opinion}

Usually people in the face of other mass information media release shall take some time to choose their concerns and needed information. Mobile Media can be customized human service information required information. Moreover, since the phone is locked target information dissemination, the arrival rate is almost $100 \%$, so in the face of something like SARS and other natural disasters such as large-scale emergencies, the national mainstream media in times of crisis can aid in the phone ensuring transparency of information, break rumors, calling people, unite the people.

\section{CHALLENGES OF MOBILE MEDIA TO BRING HIGHER EDUCATION}

\section{A. Mobile Media Challenge to The Traditional Education Model}

First, the popularity of mobile media makes the traditional education elements changed. In higher education, the popularity of mobile phones to make education a mediator and loop body into a web presence, environmental body to the center, the main object of education is also the reality of educational space into virtual space, transformed from limited to unlimited. Openness, freedom, equality and interactive features of mobile media, providing a new educational model the possibility that a student- centered individualized education model, which will help achieve people-centered philosophy of education, be individualized. This prompted higher education must abandon backward traditional mode of education, educational model for change.

\section{B. Mobile Media challenge to the traditional educational content}

Nowadays, with the changing times, mobile media has become the main channel to get people to understand the reality of the latest information, if you can not make full use of mobile phone media, you will lead to educational content obsolete, outdated, hysteresis, college students on the boring classroom content gradually excluded, while the popular online popular video and hot topics showed a keen interest. This requires that teachers must follow the propagation speed of the phone, and students to communicate good grasp of the focal point, the students spend more time learning points of interest, using a network of discourse equal dialogue with the students.

\section{Mobile Media challenge to the ideological and political education}

With college students carrying mobile phones and other platforms interact globally networked, and network information dissemination is not controllable lead mobile content varies greatly mixed, especially a lot of false information, reactionary remarks to those of life, world outlook and values in the process of formation of college students bring a lot of negative effects, easy to produce negative and pessimistic even twisted psychological conflict society, changing ideological tendencies and values, is not conducive to college world, life and values to develop, but also for the ideological and political theory course teachers more difficult.

\section{Mobile Media Challenge for College Students Self-Management Capabilities}

Education is the foundation of our country, the issue of integrity has been a big problem of the whole society. Current phone when cheating has occurred, repeated, and even in some large national exam answers there have been mass phenomenon. In order to prevent the phone cheating, schools racked, but is still facing great difficulties. Means for students to use mobile phones to cheat quite skilled, even outside the classroom installed shielded instrument, some students can still transfer data via Bluetooth in the same examination room, allowing the invigilator off guard. In addition, due to the portability of mobile phones, is not easy to find, many college students in the classroom or playing games or reading a novel or listening to music or browsing the web, doing a lot of nothing to do with the lectures, the students' cognitive ability to be strengthened, Should not extricate themselves trapped in harm imagined. 
IV. UNDER THE BACKGROUND OF MOBILE MEDIA, HIGHER EDUCATION STRATEGY TO DEAL WITH COUNTERMEASURES AND SUGGESTIONS

\section{A. Changing Concepts of Higher Education, Research and Education to Strengthen The Reform Mode}

After the popularity of mobile media, means of communication between people, learning styles have changed, prompting education model has to change. University educators must anticipate the future trends of higher education network, cultivate a good pipe network, use the network, and good use of mobile media enhanced teaching effectiveness of teachers, able to skillfully use mobile media tools to strengthen the effectiveness of teaching. For example the use of SMS, QQ, micro- letters and other chat tools close contact with students, to get feedback on the quality of students in the classroom, or on some bad words and appeared confused BBS, timely guidance and positive guidance. In this respect, the comparison leading Harvard, MIT and Stanford University, who developed a large-scale network of online courses (massive open online courses, referred MOOC) caused the Chinese higher education leaders concerned, IT sector to 2012 called China's MOOC first year, MOOC become the most popular concept. This three universities developed three MOOC platform attracted the attention of the world's people, the whole world can watch the world's top universities renowned professors learn the wonderful lectures and professors can get a certificate signed guitar lessons can even exchange credits. Many teachers think, MOOC curriculum model will lead to a huge revolution in higher education, Classroom achieved by flipping disruptive innovation, Tsinghua University and Peking University, pioneered this trend has made a quick response, decisive joined three courses open platform and cooperation with other colleges and universities are also actively take action, especially sports institutions, is expected to help resolve the long-standing pattern MOOC courses students learn training contradictions.

\section{B. Actively Expand Educational Space, A New Online} Education Initiative Occupied Positions

Mobile Media 's most prominent feature is the low immediacy and convenience, spread the cost of information transfer, without the constraints of time, universities should take this as a starting point to build a campus information on the full range of integrated communication platform construction, good management a number of beneficial physical and mental development needs of students and by the students favorite theme sites and pages to create college education "Red Net project" to build students' online spiritual home Development of micro favorite college courses, so that students do in their spare time browsing the content is no longer just entertainment, but extends curricular knowledge Or forward a number of extracurricular reading material in the micro-channel group. Additionally, you can use weibo, Micro-channel, QQ software to keep abreast of issues such as exchange students in learning and life experience. Virtual sex and occult network face to face to avoid the embarrassment and tension, so that students can freely communicate and talk. Psychological interview room through a network, QQ message boards and other tools can also keep abreast of the students' inner spiritual world, to eliminate the psychological alert students to understand the students' psychological problems and thinking problems, which has targeted to carry out moral education.

\section{Enhance The Ability of Mobile Media Network Judged Public Opinion, Strengthen The Monitoring and Guidance}

Influence public opinion on the college network should not be overlooked, as college educators to continue to enhance the level of public opinion analysis, good student guide. Students learn to use language known as network boot to work patiently and carefully, pay close attention to all kinds of students to express and forwarding information network public opinion, the correct analysis, timely guidance. For example, students in the QQ signature bar and micro-channel circle of friends remarks can be said to be a barometer of their mental state, whereby teachers can grasp the idea of dynamic students, identify problems and correct their bad behavior. Once a student on the QQ signature of said swearing, talk to her supervisor in a timely manner, on her education. Another time, a student at the micro-channel circle of friends even said a lot of guilt from shame, then, after seeing the teachers speculated that the student is certainly a setback in learning and life, quickly got to ask, the girls in the original with the opposite sex was due to the lack of experience of sexual harassment, the supervisor of the student in a timely manner to enlighten and educate.

\section{Strengthening The Capacity of Self-Education Students, Guide Students to Use Mobile Media}

As Marx put it: Everything has two sides. The popularity of mobile media has brought us a lot of convenience, but also has many negative effects. How to avoid the adverse effects, the phone becomes the key to higher education boosters forward is whether college students can correctly use the phone. Self-education is the highest level of education, personnel training is also an effective means of implementation. In the context of mobile media, and enhance the ability to select the behavior of college students and sense of responsibility is an effective way to promote higher education. Higher workers should take the initiative to establish a sense of responsibility among college students, to maintain consistency of thought and behavior, cultivate students choose and judge the ability of information, so that students can be able to cope in the ocean of information, the right choice.

\section{REFERENCES}

[1] Ministry of Industry and Information Technology. June 2012 National Health communications industry [R]. http://www.cnii.com.cn//index/content/2012-07/24/content_994750.htm.

[2] China Internet Network Information Center(CNNIC).Statistical Report on Internet Development 30th China Internet Network [R].http://www.cnnic.cn/dtygg/dtgg/201207/t20120719_32230.html.

[3] Communications World Network(CWW). In 2013 the total number of Chinese mobile phone users for the first time more than 1 billion[R].http://www.cww.net.cn/news/html/2014/1/22/2014122825299 634.htm

[4] Paul - Levinson, He Daokuan translation. Phone : Call unstoppable [M]. Beijing : China Renmin University Press,2004:05. 